\title{
Effect of Moderately Increased Intrapelvic Pressure on Renal Tissue Pressure and Vasopressin Release in Rabbits
}

\author{
Tomoyuki Shiotsu, Akira Yamamoto, Susumu Kagawa, Toshiaki Tamaki*, Yoichi Abe*, and Ian A. Reid ${ }^{* *}$
}

\begin{abstract}
Electrical stimulation of afferent renal nerves and activation of intrarenal receptors increases plasma vasopressin concentration, but the role of afferent renal nerves in the control of vasopressin secretion is not clear. Recently, we reported that activation of renal mechanoreceptors stimulates the release of vasopressin. However, intrapelvic pressure was increased to $50 \mathrm{mmHg}$, and this increase is above the normal physiological range. Therefore, in the present study, we investigated the effect of moderately increased intrapelvic pressure on plasma vasopressin concentration in anesthetized rabbits. First, we measured renal tissue pressure while intrapelvic pressure was increased stepwise in $10-\mathbf{m m H g}$ increments. Basal renal tissue pressure was $17 \pm 2 \mathrm{mmHg}$. Renal tissue pressure increased only when intrapelvic pressure was higher than the basal tissue pressure of each animal. Usually, increases in intrapelvic pressure less than $20 \mathrm{mmHg}$ did not increase renal tissue pressure. This finding suggests that only increases in intrapelvic pressure more than $20 \mathrm{mmHg}$ can activate renal mechanoreceptors. Based on this finding, the effects of moderate increases in intrapelvic pressure (15 and $30 \mathrm{mmHg})$ were studied. With a 15-mmHg increase in intrapelvic pressure, plasma vasopressin concentration did not change significantly. However, when intrapelvic pressure was increased to $30 \mathrm{mmHg}$, plasma vasopressin concentration increased from $5.6 \pm 1.4$ to $9.5 \pm 2.8 \mathrm{pg} / \mathrm{ml}$ at $5 \mathrm{~min}(p<0.05)$ and to $8.8 \pm 2.0 \mathrm{pg} / \mathrm{ml}$ at $10 \mathrm{~min}(p<$ 0.05). Plasma renin activity and mean arterial pressure also increased when intrapelvic pressure was increased to $30 \mathrm{mmHg}$. We conclude that moderate increases in intrapelvic pressure stimulate vasopressin secretion. This provides further evidence that the kidneys participate in the physiological control of vasopressin release by way of afferent renal nerves. (Hypertens Res 1995; 18: 197-202)
\end{abstract}

Key Words: afferent renal nerves, renal mechanoreceptors, renal tissue pressure, plasma vasopressin concentration, rabbit

Electrical stimulation of afferent renal nerves and activation of intrarenal receptors have been reported to increase plasma vasopressin (AVP) concentration (1-7) and the activity of the neurosecretory cells in the supraoptic $(8,9)$ and paraventricular (10) nuclei of the hypothalamus. These observation suggests that afferent renal nerves may participate in the control of the release of AVP.

Intrarenal receptors of afferent renal nerves have been classified as mechanoreceptors and chemoreceptors. Renal mechanoreceptors are activated when intrarenal pressure is increased by maneuvers including increased renal perfusion pressure, renal vein occlusion, and increased ureteral pressure (11, 12). There appear to be two types of renal chemoreceptors. R1 chemoreceptors are activated by renal ischemia, while $\mathrm{R} 2$ chemoreceptors are activated by increases in the osmolality or ionic concentration in the renal pelvis $(11,12)$.

In a previous study, we observed that activation of renal mechanoreceptors increased the release of AVP in anesthetized rabbits and that prior renal denervation attenuated this effect (5). This evidence supports the hypothesis that the kidneys participate in the control of AVP secretion by way of afferent renal nerves. However, intrapelvic pressure was increased to $50 \mathrm{mmHg}$ in that study, and this increase is above the normal physiological range. Therefore, in the present study, we investigated the effect of smaller increases in intrapelvic pressure on plasma AVP concentration. We also investigated the relationship between renal tissue pressure and intrapelvic pressure, because activation of renal mechanoreceptors presumably occurs via increased renal tissue pressure.

From the Department of Urology, the University of Tokushima School of Medicine, Tokushima, Japan and * Department of Pharmacology, Kagawa Medical School, Kagawa, Japan and ** Department of Physiology, University of California, San Francisco, CA, USA.

This research was supported by NIH Grant HL-29714.

Address for Reprints: Akira Yamamoto, M.D., Department of Urology, Takamatsu Red Cross Hospital, Ban-cho 4-1-3, Takamatsu 760, Japan.

Received August 12, 1994; accepted February 10, 1995. 


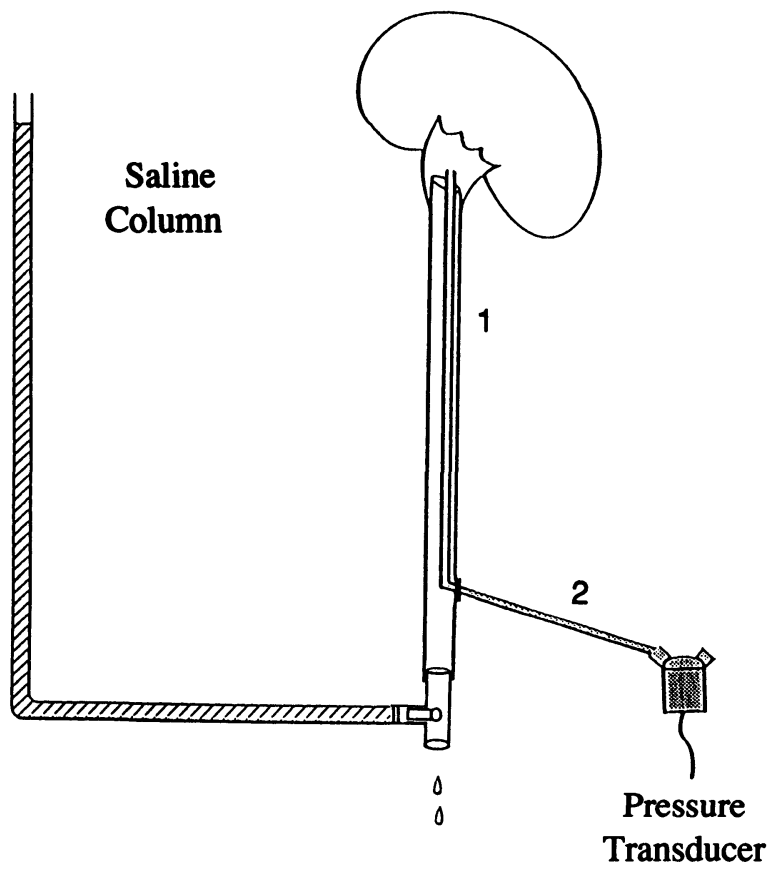

Fig. 1. Schematic drawing of the method used to increase the intrapelvic pressure.

\section{Materials and Methods}

\section{Animal Preparation}

Male New Zealand white rabbits weighing 2.5-3.4 $\mathrm{kg}$ were used. The rabbits were premedicated with acepromazine maleate $(1 \mathrm{mg} / \mathrm{kg}, \mathrm{i} . \mathrm{m}$.) and anesthetized with pentobarbital sodium $(20-30 \mathrm{mg} / \mathrm{kg}$, i.v.). Catheters were placed in the right femoral artery for monitoring arterial blood pressure and for sampling blood, and in the right femoral vein for injection of saline or anesthetic. Isotonic saline was infused at $0.1-0.2 \mathrm{ml} / \mathrm{min}$ via the femoral vein catheter to prevent dehydration during surgery. The saline infusion was stopped $30 \mathrm{~min}$ before the start of the experiment. Each rabbit was placed on its right side. The left kidney and left ureter were exposed retroperitoneally through a paravertebral incision. The left ureter was cannulated below the ureteropelvic junction with a double-lumen catheter (Fig.1). The outer sheath of this catheter (branch 1) consisted of a PE-160 catheter (Clay Adams, Parsippany, NJ) through which a PE-10 catheter (Clay Adams) was passed into the renal pelvis (branch 2). Branch 2 was connected to a Statham pressure transducer for monitoring intrapelvic pressure. The catheter tip was advanced to just above the ureteropelvic junction and fixed in place with silk threads. The distal end of the ureteral catheter was connected to a saline column via a threeway stopcock, and urine flowed freely. Special care was taken not to touch the renal hilus and to leave the renal nerves intact. In some rabbits, a 25 gauge needle connected to polyethylene tubing was inserted to the renal cortex for monitoring renal tis- sue pressure using a Statham pressure transducer. Arterial blood pressure and heart rate were continuously recorded throughout each experiment with a Statham pressure transducer and a Grass polygraph (Grass Instruments, Quincy, MA). An equilibration period of at least $60 \mathrm{~min}$ was allowed before the start of an experiment.

\section{Experimental Protocols}

Three series of experiments were performed.

1. Effect of increased pelvic pressure on renal tissue pressure $(\mathbf{n}=5)$

After hemodynamics and urine flow had stabilized, basal intrarenal tissue pressure was determined. Intrapelvic pressure was then increased stepwise in $10 \mathrm{mmHg}$ increments to a maximum of 50 $\mathrm{mmHg}$ by raising the saline column. At each increment of intrapelvic pressure, intrarenal tissue pressure was measured. The position of the tip of the needle was determined when the kidney was excised at the end of each experiment.

Based on the results of these measurements (see below), we chose 15 and $30 \mathrm{mmHg}$ increments of intrapelvic pressure for the following protocols.

2. Effect of increased pelvic pressure $(15 \mathrm{mmHg})$ on plasma AVP concentration ( $\mathrm{n}=5)$

After blood pressure and heart rate had stabilized, a $3.5 \mathrm{ml}$ control arterial blood sample was collected. Intrapelvic pressure was then increased for 10 min by connecting the ureteral catheter to the saline column in which the fluid level had been adjusted to $15 \mathrm{mmHg}$. Additional blood samples were collected 5, 10, and 30 min after pelvic pressure was increased. From each sample, a $2.7-\mathrm{ml}$ aliquot of blood was placed immediately in a chilled tube containing $0.3 \mathrm{ml} 0.3 \mathrm{M}$ EDTA. Plasma was separated by centrifugation at $4^{\circ} \mathrm{C}$ and was frozen until it was analyzed for plasma renin activity (PRA) and plasma AVP concentration. The remaining $0.8-\mathrm{ml}$ aliquot of blood was placed in a tube containing heparin for the determination of plasma osmolality. Blood samples were replaced with an equal volume of sterile isotonic saline.

At the end of experiment, the left kidney was removed together with the ureteral catheter. The kidneys were opened to confirm that the catheter tip was within the renal pelvis and that there was no damage to the mucosa membrane.

3. Effect of increased pelvic pressure $(30 \mathrm{mmHg})$ on plasma $A V P$ concentration $(\mathrm{n}=7)$

For this series of experiments, the fluid level in a saline column was adjusted to $30 \mathrm{mmHg}$. Ureteral cannulation, increasing pelvic pressure, and blood sampling were performed as described in protocol 2.

\section{Analytical Methods}

Plasma AVP concentration was determined by radioimmunoassay after extraction with bentonite (13). PRA was measured using a radioimmunoassay for angiotensin I and expressed as nanograms angiotensin I generated per ml plasma during a twohour incubation at $37^{\circ} \mathrm{C}$ and $\mathrm{pH} 6.5$ (14). Plasma osmolality was determined by freezing-point de- 


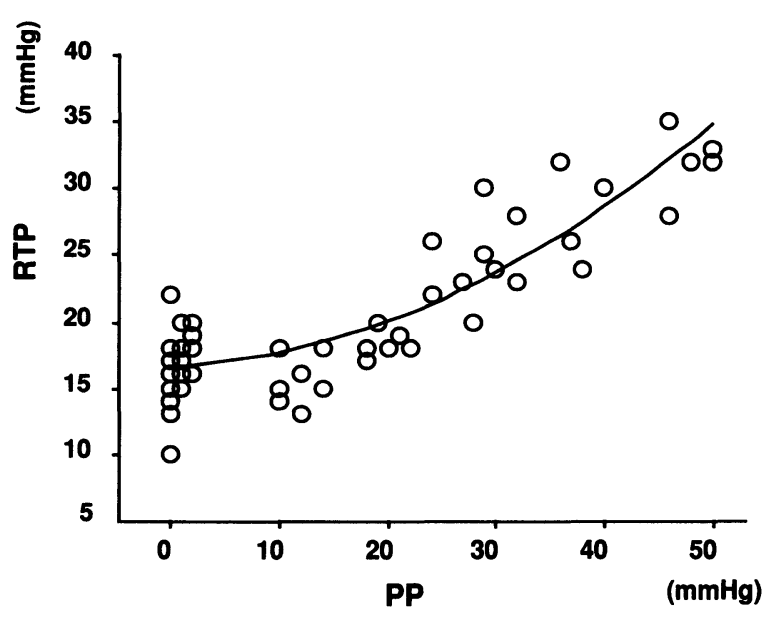

Fig. 2. Relationship between intrapelvic pressure (PP) and renal tissue pressure $(R T P)$. Curvilinear regression analysis was performed using the polynomial method. $\mathrm{y}=$ $16.561+0.048 \mathrm{x}+0.006 \mathrm{x}^{2}, \mathrm{r}=0.9, \mathrm{p}<0.01$.

pression (Advanced Model 3W).

\section{Statistical Analysis}

All results are expressed as the means $\pm \mathrm{SE}$. Multiple comparisons were performed subsequent to oneway analysis of variance for repeated measures by the Scheffe $F$-test (15). Analysis of plasma AVP concentration was made after logarithmic transformation of the data. Curvilinear regression analysis was performed using polynomial method. $p<$ 0.05 was used as the level of statistical significance.

\section{Results}

\section{Effect of Increased Intrapelvic Pressure on Renal} Tissue Pressure $(\mathrm{n}=5)$

Figure 2 shows the relationship between renal tissue pressure and intrapelvic pressure. Basal renal tissue pressure was $17 \pm 2 \mathrm{mmHg}$. Raising intrapelvic pressure increased renal tissue pressure only when intrapelvic pressure was higher than the basal tissue pressure of each animal. Usually, increases in intrapelvic pressure of less than $20 \mathrm{mmHg}$ did not increase renal tissue pressure. Renal tissue pressure increased in proportion to intrapelvic pressure $(y=$ $\left.16.561+0.048 x+0.006 x^{2}, r=0.9, p<0.01\right)$. After the period of increased pelvic pressure, renal tissue pressure returned promptly to its basal level.

\section{Effect of Increased Pelvic Pressure $(15 \mathrm{mmHg})$ on Plasma AVP concentration $(\mathrm{n}=5)$}

In this group, we investigated the effect of a $15-\mathrm{mmHg}$ increase in pelvic pressure, which did not affect renal tissue pressure, on plasma AVP concentration. Basal plasma AVP concentration was 5.6土 $0.5 \mathrm{pg} / \mathrm{ml}$. Plasma AVP concentration was $6.8 \pm 1.3$ $\mathrm{pg} / \mathrm{ml}$ at $5 \mathrm{~min}$ and $6.6 \pm 1.1 \mathrm{pg} / \mathrm{ml}$ at $10 \mathrm{~min}$ after pelvic pressure was increased to $15 \mathrm{mmHg}$ (Fig. 3). These changes in plasma AVP concentration were not statistically significant. PRA tended to increase from $8.2 \pm 1.6$ to $10.1 \pm 2.2 \mathrm{ng} / \mathrm{ml} / 2 \mathrm{~h}$ at $5 \mathrm{~min}$ and to $11.7 \pm 3.0 \mathrm{ng} / \mathrm{ml} / 2 \mathrm{~h}$ at $10 \mathrm{~min}$ (Fig. 3), but these changes were not statistically significant. The resting basal values of mean arterial pressure (MAP) and heart rate (HR) were $73 \pm 2 \mathrm{mmHg}$ and $201 \pm 12$ beats/min, respectively. Raising intrapelvic pressure to $15 \mathrm{mmHg}$ did not change MAP and HR (Fig. 3). There was no change in plasma osmolality (Table $1)$.

\section{Effect of Increased Pelvic Pressure $(30 \mathrm{mmHg})$ on} Plasma AVP Concentration $(\mathrm{n}=7)$

The renal tissue pressure measurements indicated that a $30-\mathrm{mmHg}$ increase in intrapelvic pressure increased renal tissue pressure by approximately 6 $\mathrm{mmHg}$ (Fig. 2). When pelvic pressure was increased to $30 \mathrm{mmHg}$, plasma AVP concentration increased from $5.6 \pm 1.4$ to $9.5 \pm 2.8 \mathrm{pg} / \mathrm{ml}$ at $5 \mathrm{~min}(p<0.05)$ and to $8.8 \pm 2.0 \mathrm{pg} / \mathrm{ml}$ at $10 \mathrm{~min}(p<0.05)$ (Fig. 4). PRA increased from $11.1 \pm 2.6$ to $19.9 \pm 3.4$ $\mathrm{ng} / \mathrm{ml} / 2 \mathrm{~h}$ at $5 \mathrm{~min}(p<0.01)$ and to $20.1 \pm 3.7$ $\mathrm{ng} / \mathrm{ml} / 2 \mathrm{~h}$ at $10 \mathrm{~min}(p<0.01)$ (Fig. 4$)$. MAP increased from $79 \pm 3$ to $81 \pm 3 \mathrm{mmHg}$ at $5 \mathrm{~min}(p$ $<0.01)$ and to $81 \pm 3 \mathrm{mmHg}$ at $10 \mathrm{~min}(p<0.05)$ (Fig. 4). Plasma AVP concentration, PRA and MAP all returned to their basal levels 20 min after intrapelvic pressure was decreased. HR gradually increased in some rabbits but the changes were not statistically significant. Plasma osmolality did not change significantly (Table 1 ).

\section{Discussion}

Several studies have provided evidence that afferent renal nerves contribute to the control of vasopressin release and the regulation of arterial blood pressure and renal function $(1-7,12)$. In a previous study, we examined the effects of activation of renal mechanoreceptors on the release of vasopressin (5). Plasma vasopressin concentration increased threefold when intrapelvic pressure was increased to $50 \mathrm{mmHg}$. Prior denervation of the kidneys blocked the increase in plasma vasopressin concentration produced by activation of mechanoreceptors. These results support the hypothesis that the kidneys may participate in the control of the release of vasopressin by way of afferent renal nerves. However, because a $50-\mathrm{mmHg}$ increase in intrapelvic pressure is not physiological, these results do not permit conclusions concerning the physiological role of renal receptors in the control of vasopressin release. Therefore, in the present study, we investigated the effects of smaller increases in intrapelvic pressure on plasma vasopressin concentration.

There have been several reports concerning the distribution of mechanoreceptors within the kidney. Astrom and Crafoord (16) observed an increase in the activity of afferent renal nerves when renal vein pressure was elevated in rats. They concluded that an adequate stimulus for activation of mechanoreceptors is increased intrarenal pressure and perhaps also distension of the intrarenal veins. They also observed increased afferent renal nerve activity after elevation of renal perfusion pressure and mechanical pressure applied to the hilus area in 
Table 1. Effect of Increased Intrapelvic Pressure on Plasma Osmolality

\begin{tabular}{cccccc}
\hline & & \multicolumn{4}{c}{ Plasma osmolality $\left(\mathrm{mOsm} / \mathrm{kgH}_{2} \mathrm{O}\right)$} \\
\cline { 3 - 6 } & & $0 \mathrm{~min}$ & $5 \mathrm{~min}$ & $10 \mathrm{~min}$ & $30 \mathrm{~min}$ \\
\hline $15 \mathrm{mmHg}$ & $(n=5)$ & $292 \pm 1$ & $294 \pm 3$ & $294 \pm 2$ & $295 \pm 1$ \\
$30 \mathrm{mmHg}$ & $(n=5)$ & $294 \pm 4$ & $293 \pm 3$ & $291 \pm 2$ & $292 \pm 1$ \\
\hline
\end{tabular}

Values are means $\pm \mathrm{SE}$.

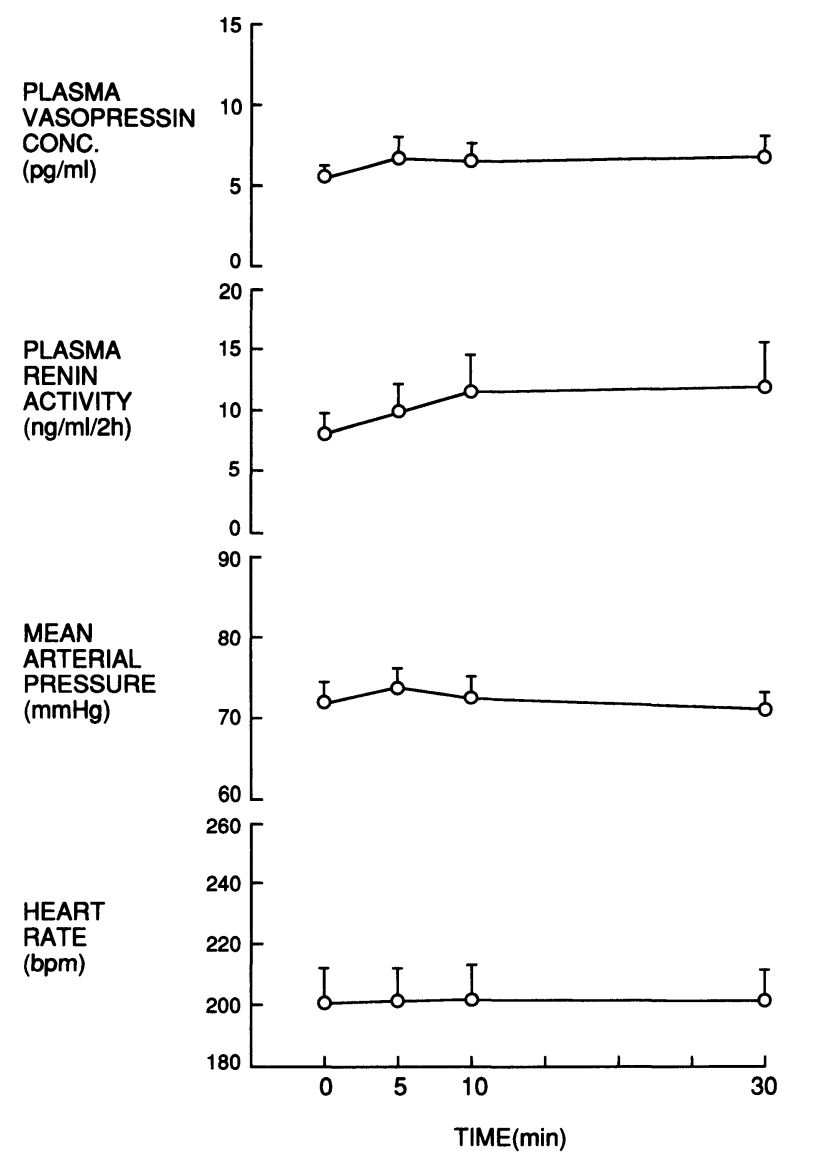

Fig. 3. Effects of increased intrapelvic pressure (15 $\mathrm{mmHg}$ ) on plasma vasopressin concentration, plasma renin activity, mean arterial pressure and heart rate. Values are means $\pm S E, \mathrm{n}=5$.

cats (17). Niijima (18) reported that mechanoreceptors responded with an increased afferent discharge rate when the arterial pressure in the kidney of rabbits increased, and that mechanoreceptors did not respond to an increase in venous pressure. He suggested that mechanoreceptors are present around the arterial walls in the kidney. He also observed that the receptors are also located in the parenchyma and in the wall of the renal pelvis (19). Recently Kopp et al. (20) found that intrapelvic administration of lidocaine did not affect the afferent renal nerve response to elevated renal venous pressure in rats, but abolished the increase in afferent renal nerve activity elicited by elevated ureteral pressure. They suggested that the mechanoreceptors activated by elevated renal venous pressure are located in an

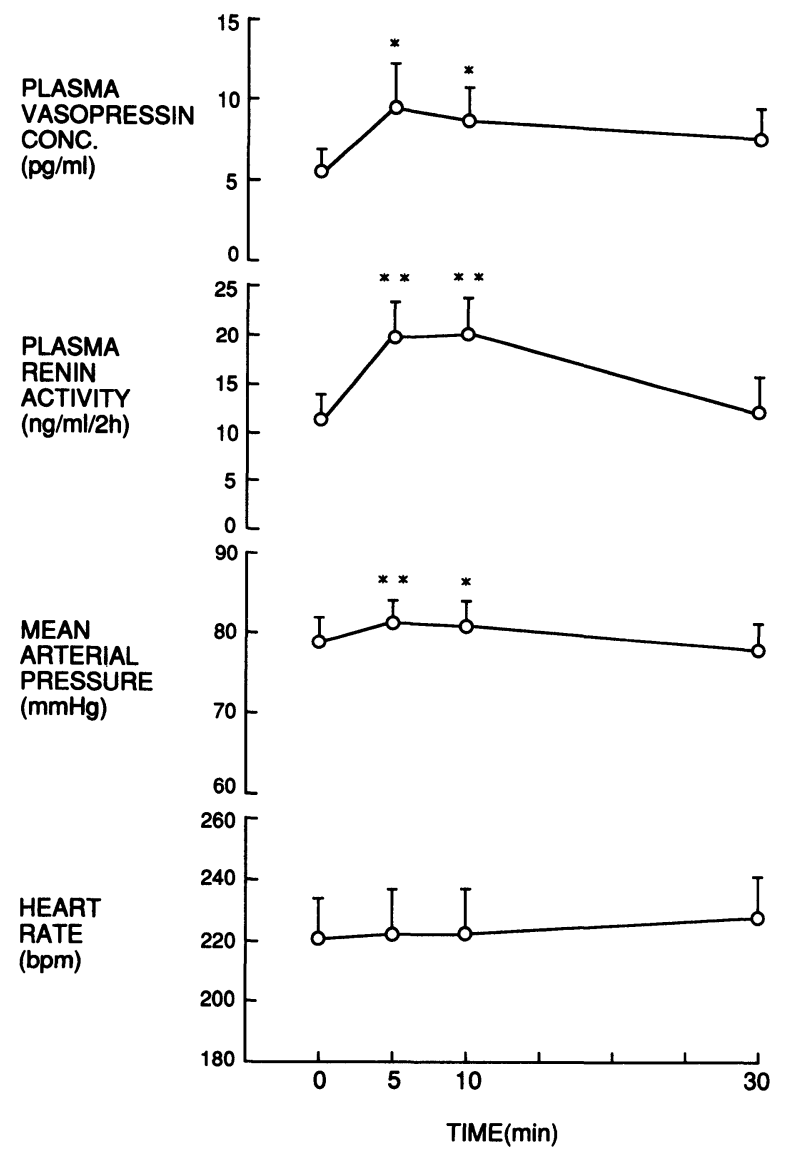

Fig. 4. Effects of increased intrapelvic pressure $(30$ $\mathrm{mmHg}$ ) on plasma vasopressin concentration, plasma renin activity, mean arterial pressure and heart rate. Values are means $\pm S E, \mathrm{n}=7 .{ }^{*} \mathrm{p}<0.05 ;{ }^{*} \mathrm{p}<0.01$ vs. 0 min.

anatomically different area than those activated by elevated pelvic pressure. The precise localization of mechanoreceptors within the kidney remains to be elucidated. Therefore, the surest method of activating renal mechanoreceptors at the present time is to increase intrarenal tissue pressure.

Activation of renal mechanoreceptors apparently occurs by way of increased renal tissue pressure. Therefore, in the present study, we examined the relationship between intrapelvic pressure and renal tissue pressure. Renal tissue pressure was $17 \pm 2$ $\mathrm{mmHg}$ under basal conditions. Yoshitoshi et al. (21) have reported a similar value $(18.4 \pm 3.1 \mathrm{mmHg})$ in rabbits. Renal tissue pressure increased only when intrapelvic pressure was higher than the basal tissue pressure of each animal. Usually, increasing in- 
trapelvic pressure by more than $20 \mathrm{mmHg}$ increased renal tissue pressure. These results indicate that intrapelvic pressure must be increased above $20 \mathrm{mmHg}$ to activate renal mechanoreceptors. Based on the present results (Fig. 2), renal tissue pressure would increase by about 6 and $17 \mathrm{mmHg}$ after intrapelvic pressure was increased to 30 and 50 $\mathrm{mmHg}$, respectively. We chose increases of intrapelvic pressure that would either not increase renal tissue pressure $(15 \mathrm{mmHg})$, or that would slightly increase tissue pressure $(30 \mathrm{mmHg})$ to examine the effect of increased intrapelvic pressure on plasma vasopressin concentration. A $30 \mathrm{mmHg}$ increase in intrapelvic pressure may be above the normal physiological range. However, Schweitzer (22) studied intrapelvic pressure in dogs with unilateral nephrectomy. Intrapelvic pressure was about 5 $\mathrm{mmHg}$ under basal conditions and increased up to $15 \mathrm{mmHg}$ under diuretic conditions without ureteral obstruction. During chronic partial ureteral obstruction, intrapelvic pressure was about $25 \mathrm{mmHg}$ under non-diuretic conditions and was elevated up to $45 \mathrm{mmHg}$ under diuretic conditions. In humans with partial ureteral obstruction due to calculi, the basal intrapelvic pressure was reported to be 25 $\mathrm{mmHg}$ and intrapelvic pressure increased to more than $50 \mathrm{mmHg}$ during flank pain (23). Thus, a $30 \mathrm{mmHg}$ increase in pelvic pressure can easily occur during partial ureteral obstruction.

With a $15 \mathrm{mmHg}$ increase in intrapelvic pressure that would not increase renal tissue pressure, plasma vasopressin concentration did not change significantly. However, plasma vasopressin concentration increased significantly after intrapelvic pressure was increased to $30-\mathrm{mmHg}$ when renal tissue pressure would increase. These results thus confirm that activation of renal mechanoreceptors can stimulate the release of vasopressin.

Plasma renin activity increased significantly when intrapelvic pressure was increased to $30 \mathrm{mmHg}$. Stimulation of vasopressin release by increased intrapelvic pressure could conceivably have been mediated via the renin-angiotensin system because angiotensin II is known to stimulate vasopressin release (24). However, in our previous study (5), renal denervation almost completely blocked the increase in plasma vasopressin concentration without preventing the increase in plasma renin activity. These results therefore suggest that the increase in plasma vasopressin concentration caused by increasing intrapelvic pressure to $30 \mathrm{mmHg}$ is mediated by way of afferent renal nerves rather than by way of the renin-angiotensin system.

The mechanism of the increase in plasma renin activity by increasing intrapelvic pressure was not investigated. One possibility is that it was mediated via macula densa mechanism (25), because glomerular filtration would have been markedly reduced so that the delivery of sodium chloride to the distal tubule would have been decreased. Another possibility is that it was mediated via increased prostaglandin synthesis, because increasing intrapelvic pressure is known to increase renal prostaglandin synthesis, and prostaglandins stimulate renin secre- tion (25). Further studies are required to investigate these possibilities.

In the present study, blood pressure increased when intrapelvic pressure was increased to 30 $\mathrm{mmHg}$. It is known that electrical stimulation of the renal nerves or activation of renal receptors increases blood pressure and heart rate $(2-4,6,12)$. These increases have generally been attributed to changes in sympathetic neural activity. However, Caverson and Ciriello (1) have recently shown that increased plasma vasopressin concentration contributes to the pressor response. Thus, the change in blood pressure in the present study may have been due both to increases in autonomic neural activity and plasma vasopressin concentration.

In summary, renal tissue pressure increased only when intrapelvic pressure was higher than the basal tissue pressure. A $30-\mathrm{mmHg}$ increase in intrapelvic pressure that would slightly increase renal tissue pressure increased plasma vasopressin concentration, while a $15 \mathrm{mmHg}$ increase that would not increase renal tissue pressure did not increase plasma vasopressin concentration. These results thus demonstrate that activation of renal mechanoreceptors by moderate increases in intrapelvic pressure increases the release of vasopressin.

\section{References}

1. Caverson MM, Ciriello J: Effect of stimulation of afferent renal nerves on plasma levels of vasopressin. Am J Physiol 1987; 252: R801-R807.

2. Simon JK, Kasting NW, Ciriello J: Afferent renal nerve effects on plasma vasopressin and oxytocin in conscious rats. Am J Physiol 1989; 256: R1240R1244.

3. Reid IA, Golin R, Gregory LC, Nolan PL, Quillen EW, Keil LC: Vasopressin, the renal nerves, and renin secretion, in Cowley Jr AW, Liard JF, Ausiello DA (eds): Vasopressin: Cellular and Integrative Functions. New York, Raven Press, 1988, pp 447-454.

4. Reid IA, Matsukawa S, Connolly M, Golin R, Keil LC: Role of the renal nerves in the control of vasopressin secretion, in Hatase O, Wang, JH (eds): BIOINFORMATICS. Information Transduction and Processing Systems from Cell to Whole Body. Amsterdam, Elsevier, 1989, pp 213-223.

5. Yamamoto A, Keil LC, Reid IA: Activation of renal mechanoreceptors increases vasopressin release in rabbits. Am J Physiol 1991; 261: R484-R490.

6. Reid IA, Yamamoto A, Keil LC, Chou L: Role of afferent renal nerves in the control of vasopressin secretion. Chin J Physiol 1991; 34: 93-104.

7. Yamamoto A, Keil LC, Reid IA: Effect of intrarenal bradykinin infusion on vasopressin release in rabbits. Hypertension 1992; 19: 799-803.

8. Day TA, Ciriello J: Afferent renal nerve stimulation excites supraoptic vasopressin neurons. Am J Physiol 1985; 249: R368-R371.

9. Day TA, Ciriello J: Effects of renal receptor activation on neurosecretory vasopressin cells. Am J Physiol 1987; 253: R234-R241.

10. Caverson MM, Ciriello J: Contribution of paraventricular nucleus to afferent renal nerve pressor response. Am J Physiol 1988; 254: R531-R543.

11. Moss NG: Electrophysiological characteristics of renal sensory receptors and afferent renal nerves. 
Miner Electrolyte Metab 1989; 15: 59-65.

12. Stella A, Zanchetti A: Functional role of renal afferents. Physiol Rev 1991; 71: 659-682.

13. Keil LC, Severs WB: Reduction in plasma vasopressin levels of dehydrated rats following acute stress. Endocrinology 1977; 100: 30-38.

14. Menard J, Catt KJ: Measurement of renin activity, concentration and substrate in rat plasma by radioimmunoassay of angiotensin I. Endocrinology 1972; 90: 422-430.

15. Winer BJ: Statistical Principles in Experimental Design. New York, McGraw-Hill, 1971.

16. Astrom A, Crafoord J: Afferent activity recorded in the kidney nerves of rats. Acta Physiol Scand 1967; 70: $10-15$

17. Astrom A, Crafoord J: Afferent and efferent activity in the renal nerves of cats. Acta Physiol Scand 1968; 74: 69-78.

18. Niijima A: Afferent discharges from arterial mechanoreceptors in the kidney of the rabbit. $J$ Physiol Lond 1971; 219: 477-485.

19. Niijima A: Observation on the localization of mechanoreceptors in the kidney and afferent nerve fibres in the renal nerves in the rabbit. $J$ Physiol Lond 1975; 245: 81-90.

20. Kopp UC, Smith LA, DiBona GF: Renorenal reflexes: neural components of ipsilateral and contralateral renal responses. Am J Physiol 1985; 249: F507-F517.

21. Yoshitoshi Y, Honda N, Morikawa A, Seki K: Alterations in the renal hemodynamics induced by increased renal vein pressure in the rabbit kidney. Jpn Heart J 1966; 7: 289-299.

22. Schweitzer FAW: Intra-pelvic pressure and renal function studies in experimental chronic partial ureteric obstruction. Br J Urol 1973; 45: 2-7.

23. Michaelson G: Percutaneous puncture of renal pelvis, intrapelvic pressure, and the concentrating capacity of the kidney in hydronephrosis. Acta Med Scand 1974; 559: 1-26.

24. Reid IA: Actions of angiotensin II on the brain: mechanisms and physiologic role. Am J Physiol 1984; 246: F533-F543.

25. Hackenthal E, Paul M, Ganten D, Taugner R: Morphology, physiology, and molecular biology of renin secretion. Physiol Rev 1990; 70: 1067-1116. 